\title{
Local variation in helminth burdens of Egyptian spiny mice (Acomys cahirinus dimidiatus) from ecologically similar sites: relationships with hormone concentrations and social behaviour
}

\author{
C.J. Barnard ${ }^{1 *}$, E. Sayed ${ }^{3}$, L.E. Barnard ${ }^{1 \dagger}$, J.M. Behnke ${ }^{2}$, \\ I. Abdel Nabi ${ }^{3}$, N. Sherif ${ }^{3}$, A. Shutt ${ }^{2}$ and S. Zalat ${ }^{3}$ \\ ${ }^{1}$ Animal Behaviour and Ecology Research Group, and ${ }^{2}$ Infection and \\ Immunity Research Group, School of Life and Environmental Sciences, \\ University of Nottingham, University Park, Nottingham, NG7 2RD, UK: \\ ${ }^{3}$ Department of Zoology, Faculty of Science, Suez Canal University, \\ Ismailia, Egypt
}

\begin{abstract}
Populations of Egyptian spiny mice (Acomys cahirinus dimidiatus) in a fragmented montane wadi system in the Sinai showed significant differences in the abundance of gut helminths. Differences in parasite load between populations were positively associated with measures of androgen activity but showed no significant relationship with glucocorticoid activity. Social discrimination tests with adult males from different wadis showed that those from sites with greater helminth abundance were less likely to investigate odours from other males and were less aggressive when subsequently interacting with the odour donors. Subjects showed markedly more investigation towards the odours of males from distant wadis compared with those from their own or immediately neighbouring wadi, but were less aggressive when confronted with odour donors from distant wadis. Despite this, there was a positive relationship between the amount of investigation towards distant male odour and subsequent aggression towards the male. While aggressiveness was positively associated with measures of androgen and glucocorticoid activity, no significant relationship emerged with individual helminth infection. Thus aggressiveness appeared to relate to overall local population levels of infection rather than individual challenge.
\end{abstract}

\section{Introduction}

The idea that susceptibility to infection, and thus the prevalence and intensity of disease in host populations,

*Fax: (++44) 1159513251

E-mail: christopher.barnard@nottingham.ac.uk

tCurrent address: Epidemiology Group, Faculty of Veterinary Science, University of Liverpool, Leahurst, Neston, Cheshire, CH64 7TE, UK reflects adaptive variation in investment in the immune system (so-called 'ecological immunology' (Sheldon \& Verhulst, 1996)) has gained considerable support in recent years (Behnke et al., 1992; Folstad \& Karter, 1992; Sheldon \& Verhulst, 1996; Barnard \& Behnke, 2001). Evidence from both field and laboratory studies suggests that immunity may be traded off against other components of life history, or, conversely, constrain investment in other components, and that, in birds and mammals, steroid hormones play an important mediating role (Grossman, 1985; 
Alexander \& Stimson, 1988; Folstad \& Karter, 1992; Wedekind \& Folstad, 1994; Wilckens \& de Rijk, 1997). Such a view has profound implications for the evolution of host-parasite relationships and the epidemiology of parasite-related disease since it suggests that resistance may vary strategically and not simply through chance (genetic or environmental) variation in immunocompetence or exposure to infection.

We have provided extensive experimental evidence for strategic modulation of immunocompetence in relation to social rank in male laboratory mice (e.g. Barnard et al., 1996a,b; 1997a,b, 1998a,b; Barnard \& Behnke, 2001). High ranking males, for example, dissociate secretion of testosterone from measures of current immune responsiveness and incur a testosterone-dependent reduction in resistance to a subsequent infection with Babesia microti. The opposite is the case for low ranking males. High rankers also maintain high levels of aggression, which are associated with reduced resistance to infection (Barnard et al., 1996a; Smith et al., 1996). However, both high and low ranking males tend to modulate testosterone secretion and/or behaviours associated with immune responsiveness (such as aggression and sleep (e.g. Barnard et al., 1997a,b; Gasparotto et al., 2002)) when experimentally immunodepressed or subjected to environmental stress (Barnard et al., 1996b, 1997a,b). So far, however, the idea of strategic modulation of immunity has not been tested in the field. Indeed, there are considerable difficulties in doing so, since naturallyoccurring hosts are likely to vary genetically in susceptibility and resistance to infection, and already to have been exposed to infection, which can itself have profound effects on steroid hormone metabolism and host behaviour (e.g. Edwards \& Barnard, 1987; Edwards, 1988; Barnard \& Behnke, 1990; Kavaliers \& Colwell, 1995; Kavaliers et al., 1998). As a first step, therefore, we have tested whether males of the Egyptian spiny mouse (Acomys cahirinus dimidiatus), show associations between parasite burden, steroid hormone (androgen and glucocorticoid) activity and aggressive behaviour that are consistent with the adaptive immunity modulation.

One prediction of the adaptive modulation hypothesis is that the extent and nature of immunity modulation will vary with the selection pressure imposed by parasites during the host's evolutionary history (Behnke et al., 1992; Sheldon \& Verhulst, 1996; Barnard \& Behnke, 2001). Local population variation in parasite pressure might be expected to favour different levels of investment in immune responsiveness, either through naturally selected genetic change, or through phenotypic plasticity (reaction norms (Stearns \& Koella, 1986)) depending on the magnitude, consistency and timescale of population differences (e.g. Hazel et al., 2000). If so, we should predict a degree of covariation between local parasite burdens, steroid hormone activity and behaviours impacting on immunity. In a parallel study of bank voles (Clethrionomys glareolus) in Poland, high burden populations were characterized by high levels of plasma corticosterone and testosterone and high fluctuating asymmetry (FA) in hind foot length (a putative measure of developmental instability; e.g. Palmer \& Strobeck, 1986; Møller \& Swaddle, 1997), but reduced aggressiveness among males (Barnard et al., 2002, 2003). The results of Barnard et al.'s vole studies thus provide correlational evidence that local variation in parasite infection within populations is associated with differences in host life history characteristics, as reflected in morphological development and stress physiology, and experimental evidence that it is associated with investment in behaviour (aggression) likely to impact on immunocompetence (Barnard et al., 1996b, 1997a,b). Here, we ask whether similar relationships hold in populations of $A$. c. dimidiatus in the Sinai. As in C. glareolus, we focus on gut helminth infections, partly because these are the overwhelmingly dominant infections in the subject populations (Behnke et al., 2000), and partly because they are known to be associated with both androgen and glucocorticoid levels in the host (e.g. Wakelin \& Selby, 1974; Roberts et al., 1996).

\section{Materials and methods}

The study was carried out in the St Katherine's Protectorate, southern Sinai, an arid montane region characterized by complex systems of dry valleys (wadis) and plains (Hobbs, 1995; Zalat \& Gilbert, 1998; Behnke et al., 2000). We chose two pairs of wadis: El Arbaein and Tofaha, close to the Suez Canal University Environmental Research Centre at St Katherine (Behnke et al., 2000), and Abu Seila and Boqueia, some $5 \mathrm{~km}$ to the north across the Plain of El Raha. The wadis were selected as neighbouring pairs (i.e. with neighbouring mouths onto the Plain of El Raha) to test for gene flow between local populations (C.J. Barnard et al., unpublished) and effects of separation on responses to social odours and interactions in A. c. dimidiatus.

Mice were trapped in each wadi during August and September 2001 using Sherman small mammal traps (H.C. Sherman Inc., Tallahassee, USA). Sixty-eight traps were set in the boulder debris in each wadi at sites identified as active from the presence of fresh faeces and disturbed soil. Traps were set each night for 22 consecutive nights and inspected at dawn, whereupon all traps were removed until the following evening. On inspection, animals were weighed, measured and ear punched (samples stored immediately in 20\% DMSO in saturated saline) on site, and a maximum of $35 \%$ of the catch (excluding lactating or pregnant females) retained for later participation in behavioural tests (adult males only; see later) and/or autopsy. All remaining animals were immediately released at their site of capture. The following morphometric measures were taken from each animal (see Barnard et al., 2002): the maximum length of the skull from the nose to the back of the cranium, the maximum width of the skull at the zygomatic arches, the length of the body from nose to anus, the length of each hind foot (measured twice to control for measurement error in relation to bilateral asymmetry (Palmer \& Strobeck, 1986)) and anogenital distance (suggested to correlate with androgenization early in development (Drickamer et al., 1995; Palanza et al., 1995)).

Retained animals were returned to the Research Centre at St Katherine, where adult males were housed singly in standard polypropylene laboratory cages $(20 \times 13 \times 10 \mathrm{~cm})$ with sawdust substrate $\left(500 \mathrm{~cm}^{3}\right)$ and 
ad libitum food (standard rodent pellet and grain) and water. Males from each wadi were housed in a separate room on a natural light/dark cycle and at ambient temperature with freely-circulating outside air. Owing to variation in capture rate between wadis, and the ceiling on retained animals, a total of 9 (El Arbaein), 9 (Tofaha), 8 (Abu Seila) and 5 (Boqueia) males were eventually retained for testing.

All other retained males and all females were culled and weighed and immediately blood sampled (using $44 \mu \mathrm{l}$ heparinized capillaries) by cardiac puncture. The entire alimentary canal was removed and placed in vials containing $10 \%$ formaldehyde, and liver, lungs and body cavity carefully inspected for helminths, which, when present, were removed and counted. The alimentary canal was carefully dissected and examined later at the University of Nottingham, and all parasites removed, identified and preserved in $70 \%$ ethanol. The spleen, kidneys, adrenal glands, thymus gland and, in males, testes and seminal vesicles were removed and weighed. Right and left paired glands were weighed separately. The weight of the seminal vesicles has been shown to be associated with circulating testosterone levels in several species of rodent (Fukazawa \& Iguchi, 1999; Desai \& Kondaiah, 2000; Jarred et al., 2000), and gonadal hormones generally have been implicated in sex differences in disease resistance (e.g. Klein, 2000). Thymus size and activity reflect immune potential and are influenced by circulating concentrations of steroid hormones (Grossman, 1985), while the size of the spleen can be affected by glucocorticoid levels and haemopoiesis and erythrophagocytosis arising from infections (Phillips, 1969; Irvin et al., 1981; Barnard et al., 1993). Blood samples were centrifuged and the resulting serum frozen at $-20^{\circ} \mathrm{C}$ for later hormone assays.

\section{Experimental procedure}

Males used in the experiment were allowed a minimum of three days to settle in their cage before a blood sample (pre-test sample) was taken from the tip of the tail in a $44 \mu \mathrm{l}$ heparinized capillary, centrifuged and the serum stored for later assay as above. All tests were conducted in a separate room in the field station during the evening (approx. 1900-0030 h), to take account of the largely nocturnal activity peak of $A$. c. dimidiatus. The test area was illuminated by a $40 \mathrm{~W}$ red lamp throughout. The test procedure was adapted from the method of Hurst et al. (1996a) for resident-intruder dyads of aboriginal house mice (Mus spretus). Twenty-eight males (8, 8, 6 and 4 from El Arbaein, Tofaha, Abu Seila and Boqueia respectively) were allocated as 'residents' (see below) for the purposes of testing, and paired with one 'intruder' male from each of three wadis, so that each resident experienced an intruder from its own wadi, its neighbouring wadi, and one of the wadis from the distant pair. Pairings were arranged so that males within dyads encountered each other only once. All residents were used as an intruder for another male, but with a minimum of $24 \mathrm{~h}$ between tests in the two roles (see also Hurst et al., 1996a).

Twenty-four hours before testing, each resident was established singly in an aluminium arena $(30 \times 30 \times$ $30 \mathrm{~cm}$ ) divided into two compartments by an opaque partition with a vertically sliding door. Ad libitum food and water were provided in the rear compartment. Three clear Perspex tubes $(20 \times 4 \mathrm{~cm})$, each end of which could be sealed with a solid or wire mesh stopper, extended from apertures in the front compartment. The resident was allowed free access to both compartments for the $24 \mathrm{~h}$, during which the internal entrances to the tubes were sealed with the solid stoppers.

\section{Odour tests}

At the end of this period, the resident was confined to the rear compartment for $5 \mathrm{~min}$ during which $50 \mathrm{~cm}^{3}$ of soiled sawdust (taking care to exclude fragments of food) from the cage of one of the resident's allocated intruders was spread inside each of the tubes. Which tube received the home, neighbouring or distant wadi intruder's sawdust was randomized across residents. Each tube was fitted with a wire mesh stopper at the distal end but was open inside the arena. A small fan blew a gentle current of air through the tubes from outside the arena. After $5 \mathrm{~min}$, the resident was allowed to enter the front compartment and the number of times it sniffed at, or entered, each of the tubes, along with the duration and extent (e.g. head only, entire body and tail) of each entry was dictated in real time onto magnetic tape for a further $5 \mathrm{~min}$. The resident was then confined once again in the rear compartment, and the tubes were removed, washed thoroughly in detergent, dried and replaced in the apertures with solid stoppers.

\section{Intruder exploration and interaction tests}

Immediately following the odour tests, the first donor intruder was introduced into the front compartment (while the resident was confined in the rear) and allowed to explore the compartment for $5 \mathrm{~min}$. During this time the number of sniffs directed by the intruder at the floor, walls and ends of the tubes, and the occurrence and location of rearing up the walls (a behaviour associated with escape tendency in other rodents (Hurst et al., 1996b); table 1), was recorded onto tape. After the period of exploration, the door between the two compartments was raised and the resident and intruder allowed to interact for a further $5 \mathrm{~min}$, during which all aggressive

Table 1. Behaviour categories recorded during social interaction tests. See text.

\footnotetext{
Anogenital sniffing - olfactory investigation of the anogenital region of the opponent.

Following - the subject followed a retreating opponent with the nose maintained close to the opponent's anogenital region.

Chasing - the subject pursued the opponent as it moved away. Biting - the subject bit the opponent.

Fleeing - the subject retreated rapidly from the opponent. Defensive upright/sideways - the subject stood upright on hind legs with head facing away from the opponent (Defensive upright), or maintained all four feet on the substrate, presenting its flank to the opponent with the body curving away (Defensive sideways).

Rearing - the subject reared up against the wall of the arena while standing on its hind legs.
} 
interactions between the two were recorded (see below). Following interaction, the arena was wiped with detergent to remove any pools or streaks of urine left by the intruder, but it was not cleaned completely in order to ensure the resident's odour was present on the substrate for remaining tests. The procedure was then repeated for the second intruder, and finally the third. Intruders were returned to their home cage immediately after their interaction test. The order in which home, neighbouring and distant intruders were introduced followed the leftright order of the three odour samples in the tubes and was thus randomized across residents.

Six categories of aggressive and defensive behaviour were recognized, broadly concurring with those in wild (Mus domesticus) and laboratory (M. musculus) house mice (Mackintosh, 1981; Hurst et al., 1994; Barnard et al., 1997a,b; table 1). Most interactions involved anogenital sniffing, following and chasing. Biting was very rare, and interactions were stopped immediately if aggression became escalated, or either individual was persistently harried. Only five out of 84 interactions had to be terminated for these reasons. No individual was injured in any way as a result of interactions during tests. Following their last intruder test, a second blood sample (post-test sample) was taken from each resident and stored as for the pre-test sample. Residents were then returned to their home cage and all cages returned to the room allocated to their wadi. When all tests had been completed, experimental animals were weighed again, then culled, measured and autopsied as above, and a final sample of blood (terminal sample) taken by cardiac puncture. All serum samples were later analysed for testosterone and cortisol (the major glucocorticoid in Acomys (Lamers et al., 1986)) concentrations using ASD (USA) ELISA kits.

\section{Statistical analysis}

The results were analysed using Statgraphics Plus v. 7 (Manugistics Inc., Maryland, USA). Parametric statistics were used where data (transformed as $\log _{10} x, \log _{10} x+1$ or square root $x$ where necessary) conformed to a normal distribution. Where data could not be normalized, nonparametric tests were used.

\section{Results}

The study tested the idea that differences in parasite abundance between local host populations are associated with differences in potentially immunomodulatory steroid hormone activity and aggressive behaviour (Folstad \& Karter, 1992; Sheldon \& Verhulst, 1996; Barnard \& Behnke, 2001). Before comparing populations in this way, however, we checked for any biases in age, sex ratio and body size between sites that might affect comparisons.

\section{Size, age and sex}

Principal components analysis (PCA) was carried out on the weight and morphometric measures taken (initial body weight, nose-anus length, length and width of the skull and the mean length of the hind feet) to derive a composite measure of body size (Borkowska, 1999; Barnard et al., 2002). Since the lengths of the left and right feet showed a significant unsigned asymmetry when compared with measurement error (the difference between the two successive measures of each foot; paired $t_{125}=4.86, P<0.0001$ ), and hind foot asymmetry has been shown to be associated with local population differences in parasite burdens and behaviour in other rodent species (Barnard et al., 2002), we also included hind foot asymmetry in the PCA. However, while the distribution of the signed left minus right difference did not differ from normality (Kolmogorov-Smirnov one sample $D_{\max }=0.11$. NS), the sample across wadis showed a small $(0.17 \pm 0.04(\mathrm{SE}) \mathrm{mm})$, but significant $\left(t_{125}=4.76\right.$, $P<0.0001)$ left bias, implying directional, rather than fluctuating, asymmetry in foot length (e.g. Palmer \& Strobeck, 1986; Møller \& Swaddle, 1997). There was no significant difference in measurement error between the left and right feet (paired $t_{125}=0.68, \mathrm{NS}$ ), which suggests the directional difference was not attributable to a side bias in measurement accuracy.

The first two components of the PCA accounted for $75.8 \%$ of the variance, the first correlating positively with all the measures of size $\left(r_{121}=0.64-0.93, P<0.0001\right.$ in all cases), but not with hind foot asymmetry $\left(r_{121}=-0.21\right.$, NS), the second negatively with head length $\left(r_{121}=-0.26, P<0.01\right)$ and positively with hind foot length $\left(r_{121}=0.36, \quad P<0.001\right)$ and asymmetry $\left(r_{121}=0.87, P<0.0001\right)$. A similar contrast between body size and foot asymmetry emerged in a parallel study of bank voles (Barnard et al., 2003). We therefore refer to the first component as SIZE and the second as ASYMM.

Kruskal-Wallis analysis of variance (ANOVA) by wadi revealed no difference between wadis in trap sample sex ratio $(H=0.31, \mathrm{~N}=138, \mathrm{NS})$. There was a significant difference in age category overall $(H=8.64, \mathrm{~N}=134$, $P<0.05$ ), but this was due to a slight bias towards weanlings from El Arbaein and Abu Seila, and older pregnant or lactating females from Tofaha, none of which were autopsied or used in behavioural tests, and so did not contribute to the analyses in the present paper. There was no difference between wadis in the age distribution analysed here $(H=2.12, \mathrm{~N}=60, \mathrm{NS})$. A parametric threeway ANOVA by wadi, sex and age category showed that SIZE differed significantly (and unsurprisingly) between sexes $\left(F_{1,97}=12.19, \quad P<0.001\right)$ and age categories $\left(F_{2,111}=56.49, P<0.0001\right)$, but did not differ between wadis $\left(F_{3,97}=2.56, \mathrm{NS}\right)$. A similar analysis of ASYMM showed no significant difference between wadis $\left(F_{3,96}=0.64, \mathrm{NS}\right)$, age categories $\left(F_{2,96}=0.45, \mathrm{NS}\right)$, or with sex $\left(F_{1,96}=3.06\right.$, NS). The differences remained significant or non-significant as above in all cases in the autopsied samples.

\section{Helminth infection}

Table 2 summarizes the prevalence and abundance of infection with helminth parasites in the study. The component parasite community structure in the wadis is the subject of a separate analysis (J.M. Behnke et al., unpublished) and will not be discussed further here. 
Table 2. The percentage prevalence (curved parentheses) and mean \pm SE and range (square parentheses) of abundance of helminth infections in mice from the different wadis. See text.

\begin{tabular}{lcccc}
\hline & \multicolumn{3}{c}{ Wadi } \\
\cline { 2 - 5 } & El Arbaein & Tofaha & Abu Seila & Boqueia \\
\hline Spiruridae* $^{*}$ & $3.92 \pm 0.99$ & $3.57 \pm 0.85$ & $5.67 \pm 1.05$ & $2.20 \pm 0.58$ \\
& $(63.2)[0-12]$ & $(82.3)[0-11]$ & $(80.0)[0-13]$ & $(50.0)[0-4]$ \\
Oxyuroideat & $5.45 \pm 2.36$ & $1.53 \pm 1.23$ & $30.13 \pm 25.69$ & $1.50 \pm 1.00$ \\
& $(40.0)[0-41]$ & $(23.5)[0-21]$ & $(60.0)[0-389]$ & $(25.0)[0-7]$ \\
Total nematodes & $10.55 \pm 2.59$ & $8.12 \pm 2.26$ & $38.30 \pm 20.4$ & $3.75 \pm 1.45$ \\
& $(85.0)[0-53]$ & $(82.3)[0-32]$ & $(93.3)[0-402]$ & $(50.0)[0-11]$ \\
Cestoidea (adult) & $0.45 \pm 0.19$ & $0.35 \pm 0.26$ & $1.07 \pm 0.76$ & $0.13 \pm 0.13$ \\
& $(25.0)[0-3]$ & $(11.8)[0-4]$ & $(33.3)[0-11]$ & $(12.5)[0-1]$ \\
Cestoidea (cysts) & $3.90 \pm 2.38$ & $0.88 \pm 0.82$ & $9.27 \pm 6.89$ & 0 \\
& $(16.5)[0-43)$ & $(11.1)[0-14]$ & $(18.8)[0-100]$ & 0 \\
N (hosts) & 20 & 18 & 16 & 10 \\
\hline
\end{tabular}

* Protospirura muricola, Mastophorus muris, Streptopharagus kuntzi.

+Dentostomella kuntzi, Syphacia minuta, Aspiculuris africana.

In the present study, we are concerned with variation in abundance and its relationship with endocrine activity and host behaviour as these reflect the predictions of the adaptive immunity modulation hypothesis (see also Barnard et al., 2002). As in our previous study of $A$. c. dimidiatus in the region (Behnke et al., 2000), ANOVA, with SIZE as a covariate, revealed a significant difference in overall helminth abundance between wadis $\left(F_{1,49}=3.69, P<0.01\right)$, with abundances being greater in El Arbaein and Abu Seila, than in Tofaha and Boqueia (fig. 1). The peak abundance in Abu Seila (although a different site from previously) relative to El Arbaein and Tofaha concurred with those for spirurid worms in 1997 (Behnke et al., 2000), but the relative abundances in El Arbaein and Tofaha were reversed. There was no significant difference between the sexes and no interaction. Of course, the relative abundances of the different

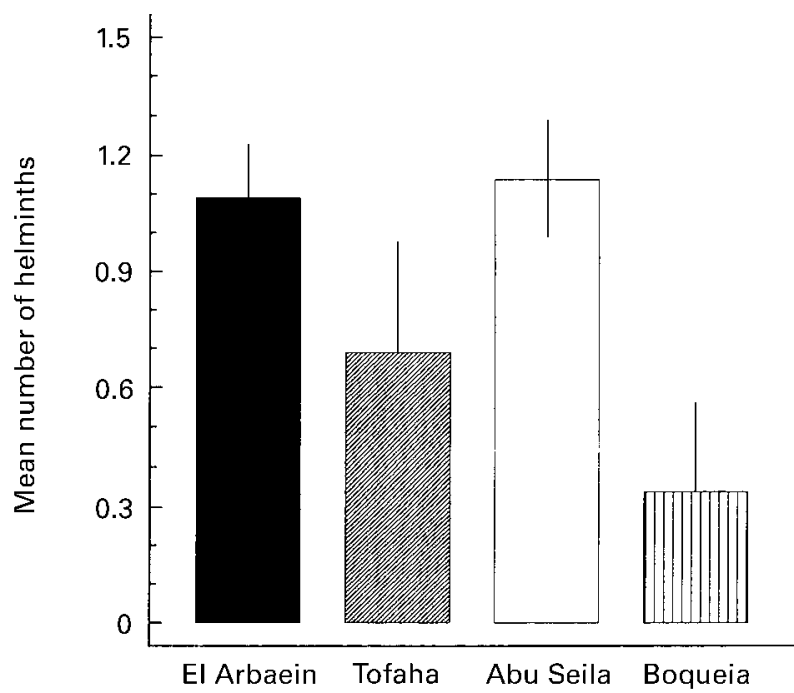

Fig. 1. The difference (from multifactor analysis of variance) in the abundance of helminths per host $\left(\log _{10} x+1\right.$ number of worms) in different wadis. Bars are standard errors. helminth groups are very different (table 1). Thus some further analyses were carried out to see whether any subset of infections had a disproportionate influence. These analyses suggested the site differences resided mainly in the total abundance of nematodes $\left(F_{1,49}=3.10\right.$, $P<0.04)$. Although spirurid abundance was significant at the $10 \%$ level $\left(F_{1,49}=2.29, P=0.09\right)$, neither oxyuroid $\left(F_{1,49}=0.66, \mathrm{NS}\right)$ nor cestode $\left(F_{1,49}=1.41, \mathrm{NS}\right)$ abundance on their own varied significantly with wadi.

\section{Organ weights and hormone concentrations}

From our previous studies of rodents, both in the laboratory (see Barnard \& Behnke, 2001) and in the field (Barnard et al., 2002), we expected differences in parasite abundance across wadis to be reflected by differences in measures of androgen and glucocorticoid activity. However, the prediction is complicated by the fact that most animals in the sample were already infected. If differences in infection are a consequence of immunodepressive hormone activity, then evidence for activity should be greater in wadis with higher levels of infection (i.e. El Arbaein and Abu Seila; fig. 1). On the other hand, if once infected, or exposed to other infected individuals, animals downregulate immunodepressive hormone activity, and/or modulate it in relation to current immunocompetence, we should expect to see less evidence of androgen activity in wadis where infection levels are high (Barnard et al., 1996a,b, 1997a,b).

To see whether hormone activity differed between wadis, we first carried out two further PCAs: one on terminal testosterone concentrations and organ weight (testes, seminal vesicles) and morphometric measures (anogenital distance) relating to androgen activity in males, and one on terminal cortisol concentrations and organ weights (adrenal weight and weight asymmetry) relating to glucocorticoid activity across both sexes. While terminal testosterone concentrations were generally low (mean $\pm \mathrm{SE}=0.43 \pm 0.02 \mathrm{ng} \mathrm{ml}^{-1}$, range $=0.33-0.83 \mathrm{ng} \mathrm{ml}^{-1}, \mathrm{~N}=37$ ), the first component derived from the PCA for androgen activity (referred to hereafter as TEST) accounted for $61 \%$ of the variance and 
was significantly positively correlated with the weights of both organs, anogenital distance and terminal testosterone concentration $\left(r_{27}=0.59-0.89, P<0.01\right.$ in all cases). The PCA for glucocorticoid activity yielded three components, all correlating significantly positively with terminal cortisol concentration (mean $\pm \mathrm{SE}=738.16 \pm$ $52.83 \mathrm{ng} \mathrm{ml}^{-1}$, range $=52.1-1586.4 \mathrm{ng} \mathrm{ml}^{-1}, \mathrm{~N}=36$ ). The third component (accounting for $22 \%$ of the variance, and referred to hereafter as CORT), however, yielded the expected association between positive correlations with cortisol concentration $\left(r_{35}=0.54, P<0.001\right)$ and adrenal gland weight $\left(r_{35}=0.53, P<0.001\right)$, and a negative correlation with adrenal gland asymmetry $\left(r_{35}=-0.35\right.$, $P<0.05$ ). As in mice (Mus musculus) (Abramov et al., 1996) and voles (Barnard et al., 2002; M. Moshkin, personal communication), adrenal gland asymmetry in A. c. dimidiatus showed a significant left bias $\left(t_{54}=2.49\right.$, $P<0.02$ ) (see also Szigethy et al., 1994; Gerendai \& Halasz, 1997). In keeping with the well-recognized association between androgen and glucocorticoid concentrations (e.g. Folstad \& Karter, 1992; Poiani et al., 2000), TEST and CORT were significantly positively correlated $\left(r_{27}=0.66, P<0.001\right)$. Each was therefore taken into account in analyses relating to the other.

ANOVA by wadi, controlling for SIZE and CORT, revealed a significant difference in TEST $\left(F_{3,21}=3.12\right.$, $P<0.05)$, with the differences in value between wadis reflecting those in helminth abundance (fig. 2, cf. fig. 1). Thus, mice from sites with the highest infections were those showing evidence of greater androgen activity. No differences emerged for CORT, however $\left(F_{3,21}=0.17\right.$, NS). ANOVA of thymus weight, controlling for SIZE, initially revealed no significant difference between wadis $\left(F_{3,40}=0.61, \mathrm{NS}\right)$. However, sex steroids are known to have a negative feedback effect on thymus activity and size (Grossman, 1985), and stepwise partial regression with SIZE, CORT and total helminth abundance as

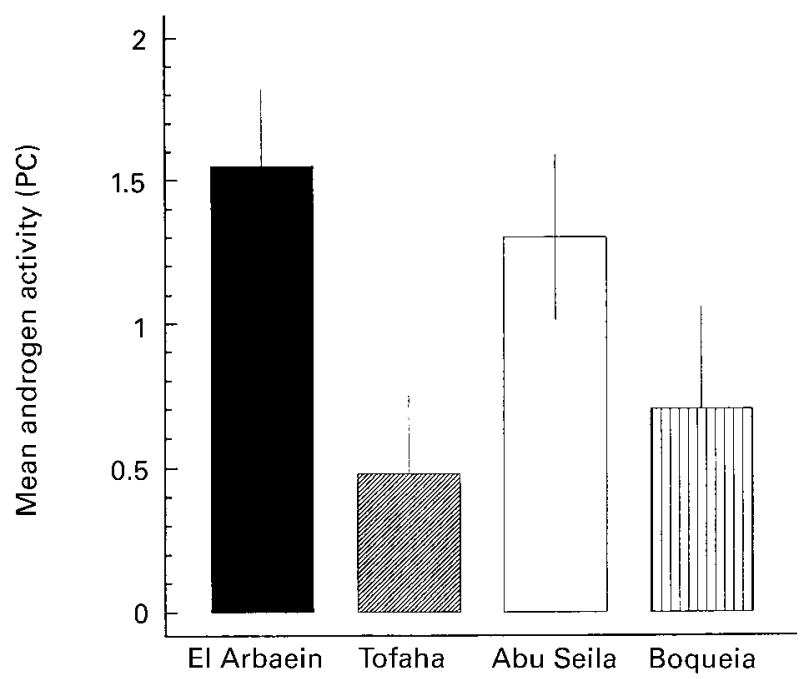

Fig. 2. The difference (from multifactor analysis of variance) in the principal component TEST (androgen activity; see text) between mice from different wadis. Bars are standard errors. additional independent variables showed a strong negative association between thymus weight and TEST $\left(t_{24}=-3.22, P<0.01\right)$. There was also a significant positive relationship with CORT $\left(t_{24}=2.56, P<0.02\right)$ but no significant relationship with helminth abundance. When the relationships with TEST and CORT were taken into account as additional covariates in the ANOVA by wadi, residual thymus weight differed significantly between wadis $\left(F_{3,18}=3.39, P<0.05\right.$; fig. 3$)$, being greater in El Arbaein and Abu Seila, where helminth burdens were higher. No significant differences between wadis, or relationships with TEST or CORT emerged for spleen weight.

\section{Response of residents to intruder odours}

To analyse the response to odours from different intruders, we carried out a further ANOVA with resident home wadi and the origin of the intruder with respect to the resident (home, neighbouring or distant wadi) as factors. Individual residents and intruders and tube position (left, centre, right) were also included as factors to control for pseudoreplication and any positional bias.

The analysis revealed a significant tendency for residents to investigate the outer two tubes more than the centre tube $\left(F_{2,19}=6.13, P<0.01\right)$. Taking this into account, there were significant effects of both resident home wadi $\left(F_{3,19}=10.31, P<0.001\right)$ and the wadi of origin of the intruder $\left(F_{2,19}=4.93, P<0.02\right)$ on investigation. Residents from the wadis with the higher infections (El Arbaein and Abu Seila) investigated tubes less than those from the other wadis (fig. 4), while residents in general investigated the odours of distant intruders more than those from home or neighbouring wadis (fig. 5a). The effects of resident wadi and the wadi of origin of the intruder remained significant when helminth burden, TEST and CORT for residents and intruders were included as covariates. None of the

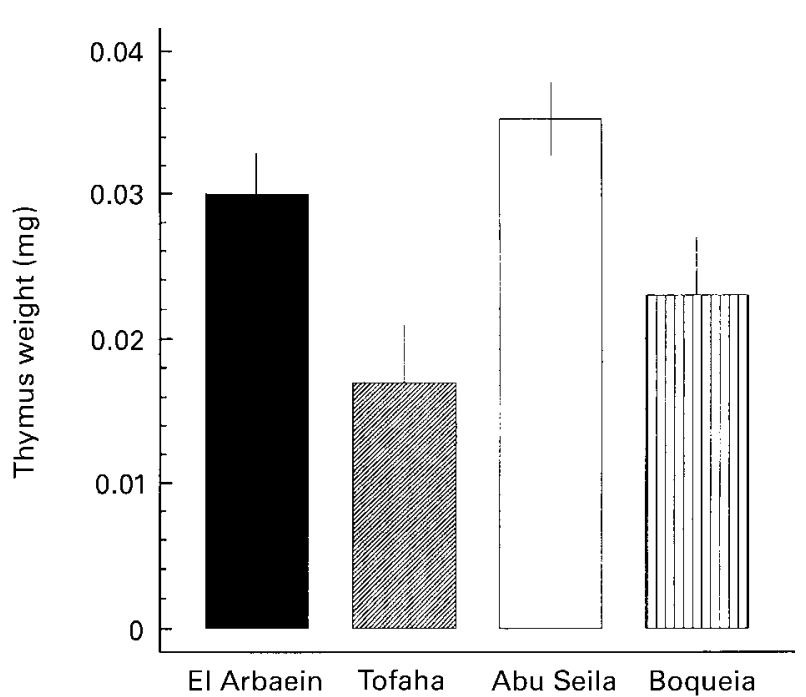

Fig. 3. The difference (from multifactor analysis of variance) in the residual thymus weight of mice from different wadis. Bars are standard errors. See text. 


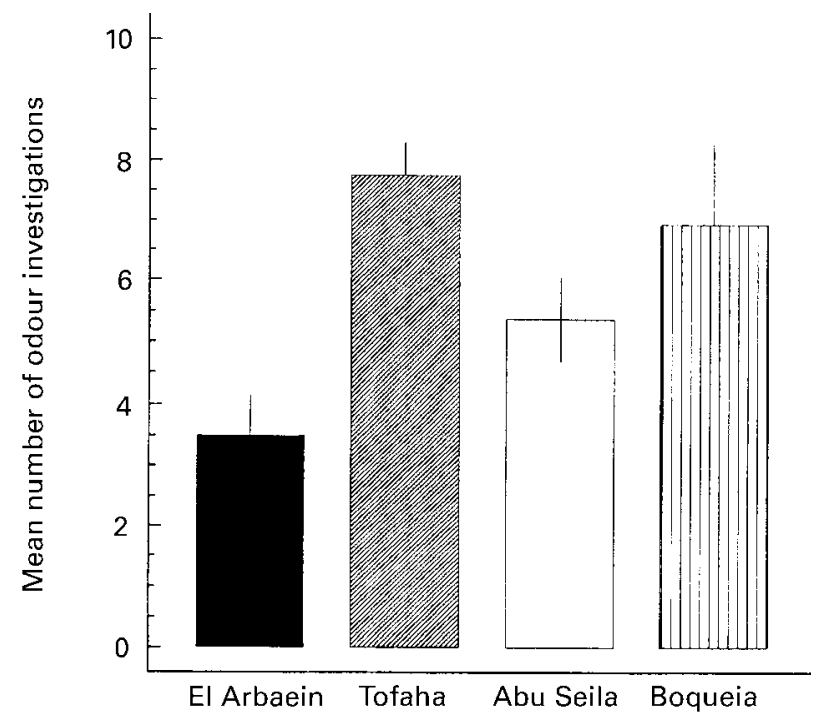

Fig. 4. The difference (from multifactor analysis of variance) in the mean number of investigations of the soiled sawdust of other males by subjects from different wadis. Bars are standard errors. See text.

covariates was significant. There was no significant effect of resident or intruder wadi on the number of entries to tubes.

\section{Response of intruders to resident odour}

A similar ANOVA for exploratory sniffing by intruders when introduced into the resident's arena prior to interaction revealed a significant effect of resident home wadi $\left(F_{3,23}=3.36, P<0.05\right)$, with intruders tending to explore the arena of residents from El Arbaein more than those of animals from other wadis. There was no significant effect of the intruder's wadi of origin (home, neighbouring, distant; $F_{2,23}=1.14$, NS) and no effect of the order (first, second or third) in which intruders were introduced in each resident's sequence of encounters $\left(F_{2,23}=2.21\right.$, NS). There was no significant effect of any factor on the tendency for intruders to rear up the walls of the arena during the exploratory phase.

\section{Aggressive interactions}

ANOVA for the number of aggressive acts (chasing, following and biting) initiated by residents showed a difference between resident home wadis in the predicted direction of fewer initiations by residents from the higher infection sites of El Arbaein and Abu Seila. While the difference just failed to reach significance $\left(F_{3,19}=2.97\right.$, $0.05<P<0.1)$ when wadis were considered separately, there was a significant difference when high (El Arbaein and Abu Seila) and low (Tofaha and Boqueia) burden wadis were combined (mean $\pm \mathrm{SE}$ number of attacks from high burden wadis $=0.46 \pm 0.06$; from low burden sites $=0.72 \pm 0.07 ; F_{1,19}=8.03, P<0.02$ ). There was also a significant effect of intruder wadi of origin, with residents initiating more aggression towards intruders from their home wadi and least towards those from a distant wadi $\left(F_{2,19}=4.26, P<0.03\right.$; fig. $\left.5 b\right)$. Initiations by intruders showed no effect of either resident home wadi $\left(F_{3,23}=1.81\right.$, NS) or whether intruders came from the resident's home, neighbouring or distant wadi of $\left(F_{2,23}=0.87\right.$, NS), and there was no significant order effect for either residents $\left(F_{2,19}=1.18, N S\right)$ or intruders $\left(F_{2,23}=0.11, \mathrm{NS}\right)$.

Stepwise partial regression analysis, controlling for helminth burden, SIZE, ASYMM, TEST and CORT, showed no significant association between the amount of investigation of an intruder's odour and subsequent aggression against the intruder when home, neighbouring and distant intruders were combined, or when home or neighbouring intruders were considered separately. However, a significant positive association emerged for distant intruders $\left(t_{21}=2.93, P<0.01\right.$; fig. 6), with residents showing more aggression towards distant intruders whose odour they had spent more time investigating. Interestingly, CORT also showed a significant positive association with aggression towards distant intruders $\left(t_{21}=2.94, P<0.01\right.$; fig. $\left.7 \mathrm{a}\right)$, but not with aggression towards home or neighbouring intruders, or all intruders combined. While no significant associations with TEST emerged, regression analysis with terminal hormone concentrations instead of PCs revealed a significant positive relationship between overall aggression by residents and terminal testosterone concentration $\left(t_{21}=2.81, P<0.02\right.$; fig. $\left.7 \mathrm{~b}\right)$. Interestingly, no significant relationships emerged between aggression and the helminth burden of individual hosts, either overall or when high and low abundance wadis were analysed separately. Thus the association between helminth abundance and aggression across wadis

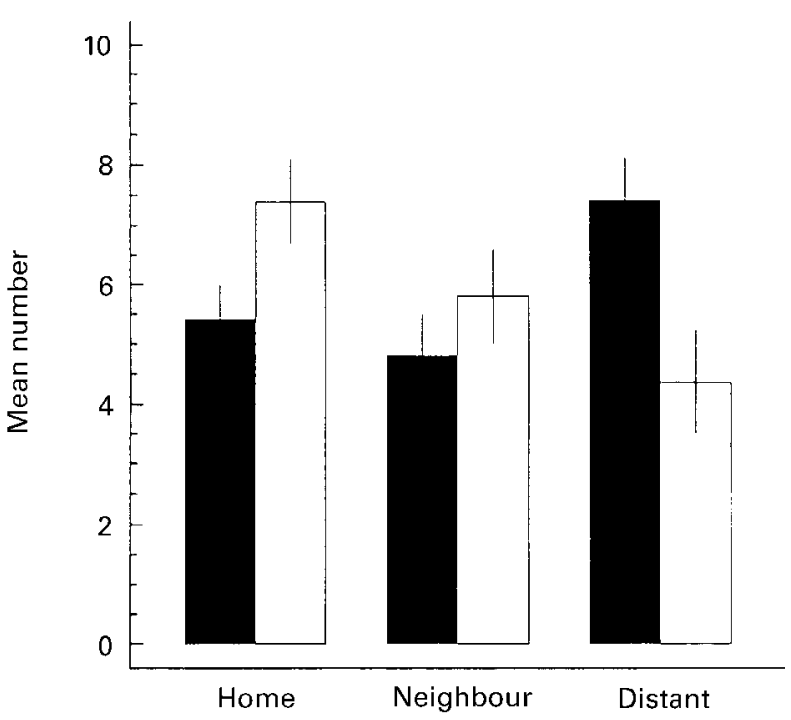

Fig. 5. The mean number of investigations (solid bars) of the soiled sawdust of males from the subject's home, neighbouring or distant wadi, and the mean number of subsequent attacks $\left(\left[\log _{10} x+1\right] \times 10\right)$ (open bars) against the odour donor (from multifactor analysis of variance). See text. Bars are standard errors. 


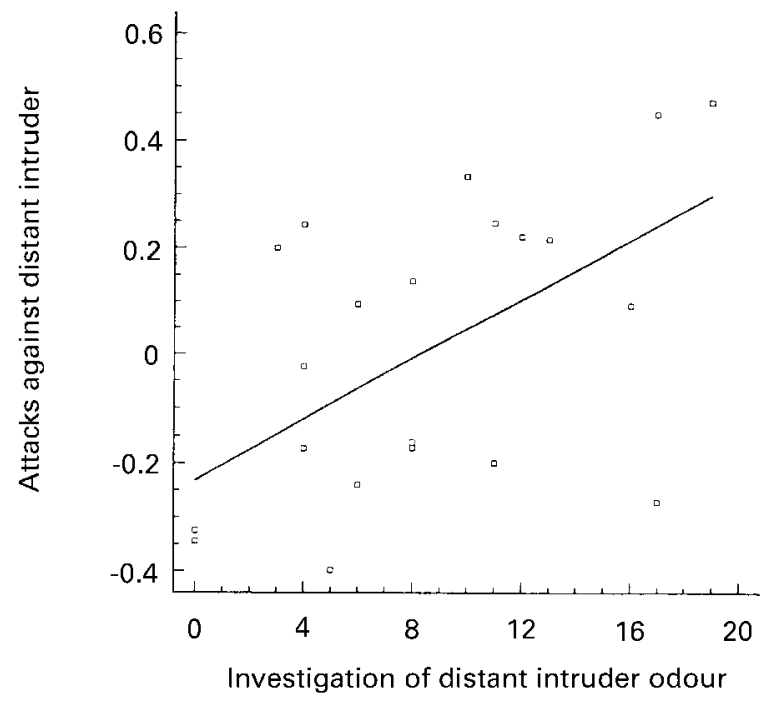

Fig. 6. Component effect from stepwise partial regression analysis for the relationship between the number of attacks $\left(\log _{10} x+1\right)$ initiated against an 'intruder' male from a distant wadi and the number of investigations of its soiled sawdust sample by the 'resident' prior to the interaction. See text.

appeared to reflect population-level differences, rather than effects of infection on individual behaviour.

\section{Discussion}

The results provide broad support for the idea of local covariation in helminth infection, steroid hormone activity and aggressive behaviour in $A$. c. dimidiatus. However, the interpretation of this covariation is not straightforward.

Population-level comparisons between wadis showed that local differences in the intensity of helminth infection were associated positively with a composite index of androgen activity. This is consistent with other studies of rodents demonstrating negative relationships with androgen activity and resistance to infection (e.g. Klein, 2000; Barnard \& Behnke, 2001; Barnard et al., 2002), and the negative relationship between androgen measures and thymus weight in the present study. While measures of androgen and glucocorticoid activity were positively correlated, again as found in many other studies (e.g. Folstad \& Karter, 1992; Poiani et al., 2000), there was no evidence of any association between local differences in helminth intensity and glucocorticoid activity. Coupled with the lack of association between morphological asymmetry and helminth infection, the results suggest that variation in infection does not reflect differences in stress between local populations, an outcome that contrasts with our findings in bank voles, where both putative stress indicators (glucocorticoid activity and hind foot asymmetry) covaried with helminth intensity (Barnard et al., 2002). One reason for the difference between the two host species may lie in the temporal stability of selection pressures acting on local populations. In the voles, local differences in helminth intensity, androgen and glucocorticoid activity and
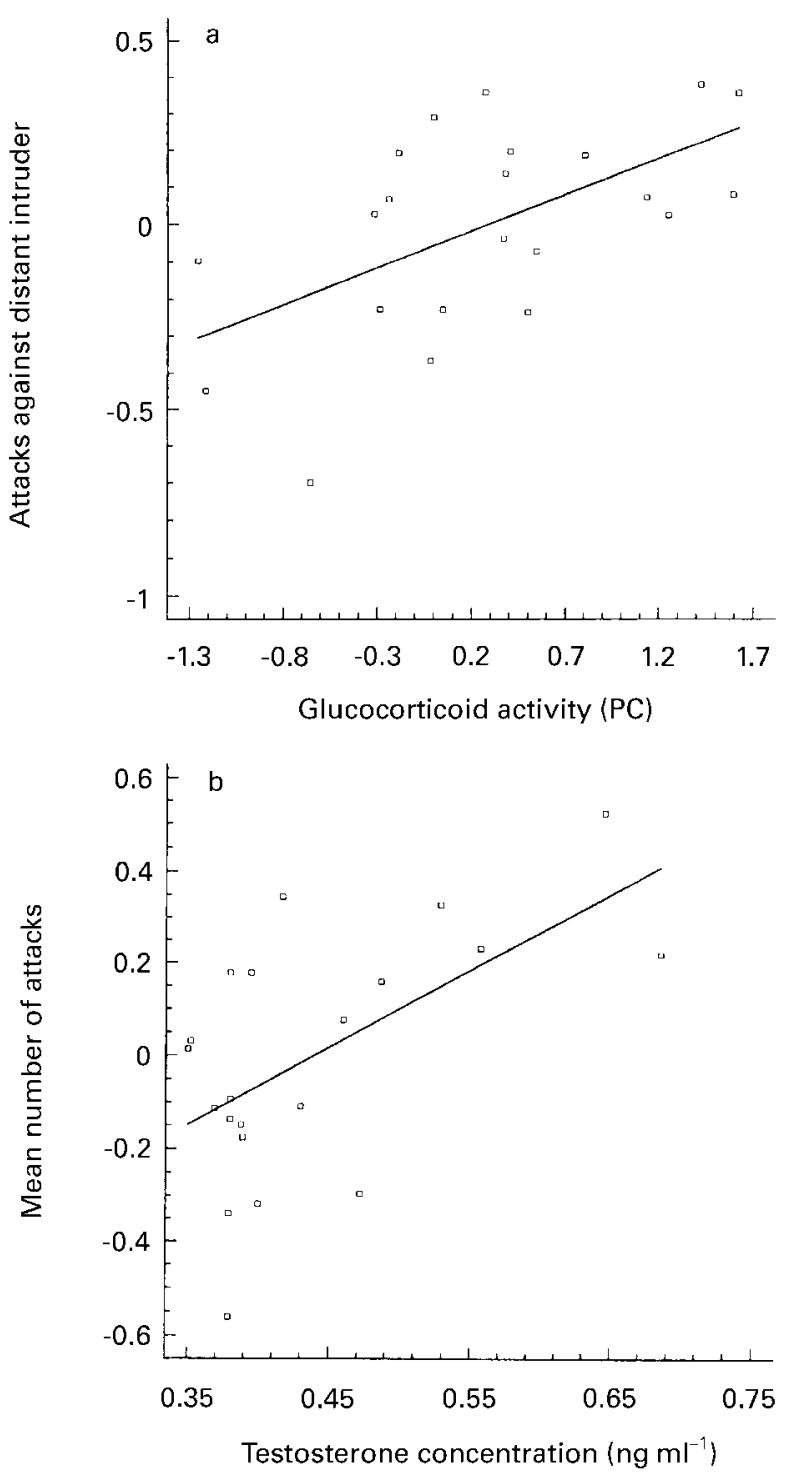

Fig. 7. Component effects from stepwise partial regression analysis for the relationships between the number of attacks $\left(\log _{10} x+1\right)$ initiated by the 'resident' and (a) the principal component CORT (glucocorticoid activity, see text) and (b) terminal testosterone concentration. See text.

morphological asymmetry were consistent in samples separated by three years, suggesting chronic differences in selection pressure (Barnard et al., 2003). While relative infection levels showed some temporal consistency across wadis in spiny mice, it is clear that some wadis differed between years. Thus local conditions facing spiny mice in the St Katherine's region may be temporally more variable than those facing voles in different forest fragments in Poland.

Of course, the cause and effect reasons for the association between helminth infection and androgen activity cannot be gleaned from the present results, though one possibility is that the timing or magnitude of 
investment in reproductive activity differed between local populations, perhaps driven by differences in resource distribution or availability and leading to differences in exposure or susceptibility to infection. That testosterone concentration in experimental males correlated positively with aggressiveness in tests suggests that androgen levels may underpin competitive relationships between males. Paradoxically, however, aggressiveness overall was lower in populations from high infection/high androgen activity sites, as was interest in social odours. While a similar negative association has been found in voles, this could be interpreted in terms of differences in apparent stress between local populations (Barnard et al., 2003). No such association with stress was evident here (see above). Interestingly, in view of these differences between host species, relationships between aggressiveness and circulating (terminal) corticosterone (voles; Barnard et al., 2003) and cortisol (spiny mice) concentrations were in opposite directions: negative in the first case and positive in the second. Thus cortisol concentration appears to rise in relation to the number of attacks initiated by male spiny mice, while male voles are more likely to initiate attacks when corticosterone levels are low. This difference may be related to the different apparent impact of glucocorticoid activity on infection in the two species.

An important finding was that aggression in experimental males was not influenced by the helminth burden of the individuals themselves. Rather it was associated with the average intensity of infection in their source population. While caution in relation to the unavoidably small sample sizes is necessary, this is consistent with potentially immunodepressive behaviours being modulated in relation to perceived infection risk in the environment rather than in response to individual challenge. It is well known that parasites can affect odours and behaviour in infected hosts, and that this can provide social information to which other, non-infected, individuals respond, either behaviourally (Edwards \& Barnard, 1987; Edwards, 1988) or physiologically (Kavaliers \& Colwell, 1995; Kavaliers et al., 1998; Penn \& Potts, 1998; Fernandes, 2000; Ehman \& Scott, 2001). An interesting possibility, therefore, is that animals from high risk sites downregulate potentially immunodepressive activity in response to social information about risk, rather than, or as well as, their own current infection status. Animals at the various sites might thus be trading off investment in costly reproductive behaviours against future survival (reproductive opportunity) differently according to the infection risks to survival in their respective environments (Sheldon \& Verhulst, 1996; Barnard \& Behnke, 2001).

\section{Acknowledgements}

We thank all the staff of the Environmental Research Centre of Suez Canal University at St Katherine for their help and warm hospitality, Mohammed Shaker for kind permission to work in the St Katherine Protectorate and generously providing us with vehicles and drivers whenever needed, Mustafa Rashid El-Rafaei for his skills in catching Acomys, both in the field, and, inevitably, in the laboratory, and an anonymous referee for helpful comments on the manuscript. The work was supported by a Research Fellowship from the Leverhulme Trust to CJB.

\section{References}

Abramov, V.V., Karmatskikh, O.L., Kozlov, V.A. \& Oskina, I.N. (1996) Functional asymmetry of adrenal glands in CBA × C57BL/6 F-1 mice. Doklady Akademii Nauk 347, 831-833.

Alexander, J. \& Stimson, W.H. (1988) Sex hormones and the course of parasitic infection. Parasitology Today 4, 189-193.

Barnard, C.J., \& Behnke, J.M. (Eds) (1990) Parasitism and host behaviour. London, Taylor \& Francis.

Barnard, C.J. \& Behnke, J.M. (2001) From psychoneuroimmunology to ecological immunology: life history strategies and immunity trade-offs. pp. 35-45 in Ader, R. Felten, D. \& Cohen, N. (Eds) Psychoneuroimmunology. 3rd edn. San Diego, Academic Press.

Barnard, C.J., Behnke, J.M. \& Sewell, J. (1993) Social behaviour, stress and susceptibility to infection in house mice (Mus musculus): effects of duration of grouping and aggressive behaviour prior to infection on susceptibility to Babesia microti. Parasitology 107, 183-192.

Barnard, C.J., Behnke, J.M. \& Sewell, J. (1996a) Social status and resistance to disease in house mice (Mus musculus): status-related modulation of hormonal responses in relation to immunity costs in different social and physical environments. Ethology 102, 63-84.

Barnard, C.J., Behnke, J.M. \& Sewell, J. (1996b) Environmental enrichment, immunocompetence and resistance to Babesia microti in male laboratory mice. Physiology and Behaviour 60, 1223-1231.

Barnard, C.J., Behnke, J.M., Gage, A.R., Brown, H. \& Smithurst, P.R. (1997a) Modulation of behaviour and testosterone concentration in immunodepressed male laboratory mice (Mus musculus). Physiology and Behaviour 61, 907-917.

Barnard, C.J., Behnke, J.M., Gage, A.R., Brown, H. \& Smithurst, P.R. (1997b) Immunity costs and behavioural modulation in male laboratory mice (Mus musculus) exposed to the odour of females. Physiology and Behaviour 62, 857-866.

Barnard, C.J., Behnke, J.M., Gage, A.R., Brown, H. \& Smithurst, P.R. (1998a) The role of parasite-induced immunodepression, rank and social environment in the modulation of behaviour and hormone concentration in male laboratory mice (Mus musculus). Proceedings of the Royal Society of London Series B 265, 693-701.

Barnard, C.J., Behnke, J.M., Gage, A.R., Brown, H. \& Smithurst, P.R. (1998b) Maternal effects on the development of social rank and immunity trade-offs in male laboratory mice (Mus musculus). Proceedings of the Royal Society of London Series B 265, 2087-2093.

Barnard, C.J., Behnke, J.M., Bajer, A., Bray, D., Race, T., Frake, K., Osmond, J., Dinmore, J. \& Sinski, E. (2002) Local variation in endoparasite burdens of bank voles (Clethrionomys glareolus) from ecologically similar sites: 
morphometric and endocrine correlates. Journal of Helminthology 76, 103-112.

Barnard, C.J., Kulis, K., Behnke, J.M., Bajer, A., Gromadzka-Ostrakowska, J., Stachon, E. \& Sinski, E. (2003) Local variation in helminth burdens of bank voles (Clethrionomys glareolus) from ecologically similar sites: temporal stability and relationships with hormone concentrations and social behaviour. Journal of Helminthology 77, 185-195.

Behnke, J.M., Barnard, C.J. \& Wakelin, D. (1992) Understanding chronic nematode infections: evolutionary considerations, current hypotheses and the way forward. International Journal for Parasitology 22 861-907.

Behnke, J.M., Barnard, C.J., Mason, N., Harris, P.D., Sherif, N.E., Zalat, S. \& Gilbert, F.S. (2000) Intestinal helminths of spiny mice (Acomys cahirinus dimidiatus) from St Katherine's Protectorate in the Sinai, Egypt. Journal of Helminthology 74, 31-43.

Borkowska, A. (1999) Genetic and morphological variation among populations of the bank vole Clethrionomys glareolus from north-eastern Poland: the seasonal aspect. Zeitschrift Saugetierkunde 64, 285-297.

Desai, K.V. \& Kondaiah, P. (2000) Androgen ablation results in differential regulation of transforming growth factor beta isoforms in rat male accessory sex organs and epididimys. Journal of Molecular Endocrinology 24, 253-260.

Drickamer, L.C., Saal, F.S. vom, Marriner, L.M. \& Mossman, C.A. (1995) Anogenital distance and dominance status in male house mice (Mus domesticus). Aggressive Behaviour 21, 301-309.

Edwards, J.C. (1988) The effects of Trichinella spiralis infection on social interactions in mixed groups of infected and uninfected male mice. Animal Behaviour 36, 529-540.

Edwards, J.C. \& Barnard, C.J. (1987) The effects of Trichinella infection on intersexual interactions between mice. Animal Behaviour 35, 533-540.

Ehman, K.D. \& Scott, M.E. (2001) Urinary odour preferences of MHC congenic female mice, Mus domesticus: implications for kin recognition and detection of parasitized males. Animal Behaviour 62, 781-789.

Fernandes, G.A. (2000) Immunological stress in rats induces bodily alterations in saline-treated conspecifics. Physiology and Behaviour 69, 221-230.

Folstad, I. \& Karter, A.J. (1992) Parasites, bright males and the immunocompetence handicap. American Naturalist 139, 603-622.

Fukazawa, Y. \& Iguchi, T. (1999) Effects of hormones and growth factors on the development of the male mouse reproductive tract in vitro. Zoological Science 16, $153-160$

Gasparotto, O.C., Ignacio, Z.M., Lin, K. \& Goncalves, S. (2002) The effect of different psychological profiles and timings of stress exposure on humoral immune response. Physiology and Behaviour 76, 321-326.

Gerendai, I. \& Halasz, B. (1997) Neuroendocrine asymmetry. Frontiers in Neuroendocrinology 18, 354-381.

Grossman, C.J. (1985) Interactions between the gonadal steroids and the immune system. Science 227, 257-261.
Hazel, S.M., Bennett, M., Chantrey, J., Bown, K., Cavanagh, R., Jones, T.R., Baxby, D. \& Begon, M. (2000) A longitudinal study of an endemic disease in its wildlife reservoir: cowpox and wild rodents. Epidemiology and Infection 124, 551-562.

Hobbs, J.J. (1995) Mount Sinai. Austin, Texas, Texas University Press.

Hurst, J.L., Fang, J. \& Barnard, C.J. (1994) The role of substrate odours in maintaining social tolerance between male house mice, Mus musculus domesticus: relatedness, incidental kinship effects and the establishment of social status. Animal Behaviour 48, 157-167.

Hurst, J.L., Hall, S., Roberts, R. \& Christian, C. (1996a) Social organization in the aboriginal house mouse, Mus spretus Lataste: behavioural mechanisms underlying the spatial dispersion of competitors. Animal Behaviour 51, 327-344.

Hurst, J.L., Barnard, C.J., Hare, R., Wheeldon, E.B. \& West, C.D. (1996b) Housing and welfare in laboratory rats: tome-budgeting and pathophysiology in singlesex groups. Animal Behaviour 52, 335-360.

Irvin, A.D., Young, E.R., Osborn, G.D. \& Francis, L.M.A. (1981) A comparison of Babesia infections in intact, surgically splenectomized, and congenitally asplenic $(\mathrm{Dh} /+)$ mice. International Journal for Parasitology 11, 251-255.

Jarred, R.A., Cancilla, B., Prins, G.S., Thayer, K.A., Cunha, G.R. \& Ridbridger, G.P. (2000) Evidence that estrogens directly alter androgen-regulated prostate development. Endocrinology 141, 3471-3477.

Kavaliers, M. \& Colwell, D.D. (1995) Discrimination by female mice between the odours of parasitized and non-parasitized males. Proceedings of the Royal Society of London Series B 261, 31-35.

Kavaliers, M., Colwell, D.D. \& Choleris, E. (1998) Analgesic responses of male mice exposed to the odors of parasitized females: effects of male sexual experience and infection status. Behavioral Neuroscience 112, $1001-1011$.

Klein, S.L. (2000) Hormones and mating system affect sex and species differences in immune function among vertebrates. Behavioural Processes 51, 149-166.

Lamers, W.H., Mooren, P.G., Griep, H., Endert, E., Degenhart, H.J. \& Charles, R. (1986) Hormones in perinatal rat and spiny mouse: relation to altricial and precocial timing of birth. American Journal of Physiology 14, E78-E85.

Mackintosh, J.H. (1981) Behaviour of the house mouse. Symposium of the Zoological Society of London 47, 337-365.

Møller, A.P. \& Swaddle, J.P. (1997) Asymmetry, developmental stability and evolution. Oxford, Oxford University Press.

Palanza, P., Parmigiani, S. \& Saal, F.S. vom (1995) Urine marking and maternal aggression of wild female mice in relation to anogenital distance at birth. Physiology and Behaviour 58, 827-835.

Palmer, A.R. \& Strobeck, C. (1986) Fluctuating asymmetry: measurement, analysis, pattern. Annual Review of Ecology and Systematics 17, 391-421.

Penn, D. \& Potts, W.K. (1998) Chemical signals and parasite-mediated sexual signals. Trends in Ecology and Evolution 13, 391-396. 
Phillips, R.S. (1969) The role of the spleen in relation to natural and acquired immunity to infections of Babesia rodhaini in the rat. Parasitology 59, 637-648.

Poiani, A., Goldsmith, A.R. \& Evans, M.R. (2000) Ectoparasites of house sparrows (Passer domesticus): an experimental test of the immunocompetence handicap hypothesis and a new model. Behavioral Ecology and Sociobiology 47, 230-240.

Roberts, C.W., Satoskar, A. \& Alexander, J. (1996) Sex steroids, pregancy-associated hormones and immunity to parasitic infections. Parasitology Today 12, 382-388.

Sheldon, B.C. \& Verhulst, S. (1996) Ecological immunology: costly parasite defences and trade-offs in evolutionary ecology. Trends in Ecology and Evolution 11, 317-321.

Smith, F.V., Barnard, C.J. \& Behnke, J.M. (1996) Social odours, hormone modulation and resistance to disease in male laboratory mice. Animal Behaviour 52, 141-153.

Stearns, S.C. \& Koella, J. (1986) The evolution of phenotypic plasticity in life-history traits: predictions for norms of reaction for age- and size-at-maturity. Evolution 40, 893-913.

Szigethy, E., Conwell, Y., Forbes, N.T., Cox, C. \& Caine, E.D. (1994) Adrenal weight and morphology in victims of completed suicide. Biological Psychology 36, 374-380.

Wakelin, D. \& Selby, G.R. (1974) The induction of immunological tolerance to the parasitic nematode Trichuris muris in corticosterone-treated mice. Immunology 26, 1-10.

Wedekind, C. \& Folstad, I. (1994) Adaptive and nonadaptive immunosuppression by sex hormones. American Naturalist 143, 936-938.

Wilckens, T. \& Rijk, R. de (1997) Glucocorticoids and immune function: unknown dimensions and new frontiers. Immunology Today 18, 418-424.

Zalat, S. \& Gilbert, F.S. (1998) A walk in the Sinai: St Katherine to Al Galt al Azraq (the Blue Pool). Cairo, El Haramen Press.

(Received 7 February 2003)

(C) CAB International, 2003 